\title{
Perfil educacional de atletas em formação no futebol no Estado do Rio de Janeiro
}

CDD. 20.ed. 371.12

796.5

http://dx.doi.org/10.1590/1807-55092014000400617
Leonardo Bernardes Silva de MELO* Antonio Jorge Gonçalves SOARES*** Hugo Paula Almeida da ROCHA***

\section{Resumo}

*Centro de Educação Física e Desportos, Universidade Federal do Espírito Santo.

**Faculdade de Educação, Universidade Federal do Rio de Janeiro.

***Colégio Pedro II.

0 estudo teve como objetivo descrever o perfil escolar de atletas que atuam no Estado do Rio de Janeiro e que se encontram no período da escolarização básica. 0 estudo teve uma abordagem quantitativa e qualitativa. Foram realizadas entrevistas estruturadas com amostra não probabilística composta por 417 jogadores das categorias de base, inscritos no ano de 2009 na Federação de Futebol do Estado do Rio de Janeiro e 30 entrevistas semiestruturadas. Os resultados apontaram que os atletas permanecem na escola, todavia a troca de turno escolar e o baixo capital cultural podem afetar negativamente a sua trajetória escolar. A profissionalização no futebol torna-se um projeto familiar e talvez incida sobre o foco que o atleta tenha sobre o processo de escolarização. Os dados sugerem que quanto maior os investimentos do atleta na carreira, maior será a probabilidade de secundarizar os investimentos escolares.

PalavRas-Chave: Esporte; Escolarização; Formação profissional; Jovens atletas.

\section{Introdução}

Os estudos internacionais ao analisarem programas de conciliaçấo da carreira acadêmica com a carreira esportiva de alto-rendimento apresentam a dificuldade de conciliar essas duas carreiras para os jovens. Esse fenômeno na vida dos jovens que se dedicam ao esporte no mesmo período da formação acadêmica tem sido nomeado de dupla carreira ("dual carrer") ${ }^{1}$. Em síntese, essa literatura apresenta as seguintes constataçóes acerca da conciliação entre as rotinas do esporte e da formação acadêmica: a) os jovens atletas costumam ter dificuldade de gestão do tempo para realização das atividades esportivas em concomitância com as demandas escolares/ universitárias (tarefas acadêmicas e dedicação aos estudos); b) a necessidade das políticas públicas ou privadas em fornecer educação e capacitação para os jovens atletas integrarem-se ao mercado de trabalho após suas trajetórias esportivas, pois, tal necessidade parte do pressuposto que tanto os exatletas quanto os outros jovens terão mais chances de obtençáo de um posto de trabalho quanto maior for a qualificação educacional ${ }^{1-5}$; c) a fundamental importância do convencimento e sedução das famílias para matricularem seus filhos com potencial esportivo nesses programas voltados para formaçáo acadêmica para atletas ${ }^{6}$; d) a pouca capacidade de reconversão das experiências esportivas em funçóes ou ocupaçóes vinculadas ao mercado do esporte de espetáculo ou educacional ${ }^{3}$. Metsä-ToKILA ${ }^{2}$ sugeriu que o sucesso da combinaçáo da carreira esportiva com estudos acadêmicos, mesmo em programas internacionais cujo objetivo é mediar essa dupla formação do atleta, depende da flexibilidade com que essas instituiçóes formativas (esporte e escola) tratam os calendários de exames para atletas, os horários de estudo e de treinamento esportivo. Todavia, tais programas, segundo as análises supracitadas, tiveram êxito limitado na gestão da conciliaçáo entre as demandas esportivas e escolares.

No Brasil, as agências de formação esportiva agem de forma livre e devem apenas obedecer o preceito legal, junto com as famílias, de manter as crianças e jovens matriculadas na escola básica ${ }^{7}$. A literatura nacional não descreve nenhum programa universitário de combinaçáo entre formaçáo esportiva de alto-rendimento e universitária. A única 
experiência pública de conciliação de formação esportiva com a escolarização básica é recente. Essa experiência embrionária é conhecida como GEO (Ginásio Experimental Olímpico) e se trata de uma escola vocacionada dentro da rede municipal de ensino do Rio de Janeiro e atende ao público do segundo segmento do ensino fundamental ${ }^{2}$. Ainda no Brasil, outros exemplos dessa natureza partem da iniciativa privada de clubes ou federaçôes que oferecem escolarização básica para atletas em escolas no interior das instituiçóes clubísticas ou através de convênios com escolas privadas ${ }^{\mathrm{b}}$. Nesse sentido, as análises empreendidas sobre a formação acadêmica de atletas no Brasil tem se baseado no levantamento e entendimento de como essa dupla carreira tem sido administrada no cotidiano dos atletas junto às escolas, universidades, clubes e federaçóes. Todavia, cabe destacar que ainda não temos tradição, tanto em nível internacional quanto nacional, em tratar essa dupla carreira como um objeto de estudo específico.

Vejamos o cenário brasileiro. EPIPHANIO ${ }^{8}$ destacou as dificuldades dos atletas ${ }^{c}$ e os conflitos em suas vidas para desenvolverem a carreira esportiva. Um dos conflitos apontados está relacionado às renúncias que os atletas devem fazer aos aspectos do lazer e da convivência social em função da carreira. MARQUES e SAMUSKI ${ }^{9}$ indicaram que, no momento de transição entre o amadorismo e o profissionalismo dos jovens atletas de futebol (masculino), os jovens atletas se ressentem do afastamento familiar por residirem em albergues, da falta de apoio e acompanhamento da escolarização e da necessidade de adaptação dos currículos escolares frente às necessidades especiais

\section{Método}

\section{Sujeitos}

A população do estudo estimada, a partir da organização do futebol em 2009, era de 5.495 atletas, segundo dados da Federaçáo de Futebol do Estado do Rio de Janeiro (FERJ). Consideramos a proporçáo de atletas inscritos por categoria e estabelecemos os seus respectivos $\mathrm{N}$ amostrais a serem investigados, conforme TABELA 1. Para calcular o tamanho da amostra foi considerado dos atletas e dos trabalhadores em geral. Souza et al. ${ }^{10}$ indicaram a dificuldade de reconversão profissional para a trajetória dos malsucedidos na carreira de jogadores de futebol a partir das histórias de vida de dois atletas. Soares e Melo ${ }^{11}$ e SoAres et al. ${ }^{12}$ também apontaram para a alta carga de treinamento destinada à formação de jovens atletas no futebol, a ausência de supervisão pedagógica sobre o desempenho escolar dos atletas e a prioridade dada ao futebol em relação à formação escolar. Diante das evidências presentes na literatura que indicam a dificuldade de conciliaçấo entre a formação escolar e a esportiva nessa dupla carreira, buscamos entender se a formação profissional no futebol afasta, dificulta ou cria obstáculos para permanência ou dedicação do atleta na escola básica. Utilizou-se, neste estudo, o método nãoprobabilístico casual para a seleção da amostra e levamos em consideração que os clubes do Rio de Janeiro estáo entre os mais importantes centros formadores de atletas para o futebol brasileiro.

A crença presente no senso comum é a que os jogadores de futebol têm poucos anos de escolaridade em função do longo processo de profissionalização no esporte. Por essa razão, as questôes que nos orientaram ao longo da pesquisa foram as seguintes: a formação dos atletas para o futebol nas categorias de base cria empecilhos para o processo de escolarização? Os atletas de futebol das categorias de base possuem atraso escolar em relação à população da mesma idade? Como os atletas das categorias de base do futebol no Rio de Janeiro priorizam suas rotinas de treinamento e estudos? um nível de significância de 0,05 e um poder de teste de 0,95 . A amostra foi formada por 417 jogadores estratificados pelas categorias de base sub-13, sub-15, sub-17 e sub-20, inscritos no ano de 2009 na FERJ.

A participação dos sujeitos foi consentida por seus responsáveis através da assinatura de um termo de consentimento livre e esclarecido previamente aprovado pelo comitê de ética institucional (Universidade Gama Filho, Protocolo n. 017.2007). 
TABELA 1 - Distribuição da amostra da pesquisa.

\begin{tabular}{lcccc}
\hline Categoria & Número de clubes & Média de atletas inscritos por clube & Total & Amostra da pesquisa \\
\hline Sub -13 & 15 & 35 & 525 & 76 \\
Sub - 15 & 39 & 35 & 1365 & 113 \\
Sub - 17 & 41 & 35 & 1435 & 119 \\
Sub - 20 & 70 & 30 & 2100 & 109 \\
Total & --- & --- & 5495 & 417 \\
\hline
\end{tabular}

\section{Delineamento}

Realizamos um estudo observacional de corte transversal no sentido de entender como os jovens conciliam a formação no futebol e sua escolarização. As 417 entrevistas estruturadas foram registradas por escrito, em formulário próprio, pela equipe de pesquisadores em contato direto com os atletas, antes ou após os treinamentos nos clubes. Realizamos 30 entrevistas semiestruturadas e também utilizamos sistematicamente registros em diário de campo para conversas mais aprofundadas com atletas e com os responsáveis dos clubes. Essa dimensão qualitativa do estudo teve a função de entender o significado das açôes dos atletas na conciliação entre futebol e escola ou serviram para exemplificar algum detalhe corroborativo na argumentação e na interpretação dos dados.

\section{Instrumento}

O formulário de entrevistas estruturadas foi construído a partir de estudos exploratórios sobre o tema e validado em um estudo piloto no qual entrevistamos 10 atletas das diferentes categorias. Neste estudo piloto realizou-se, além da validação dos instrumentos, também o treinamento de pesquisadores. Após a análise do piloto, pela equipe e por três doutores especialistas na área, chegamos à versão final do instrumento que tratou dos seguintes pontos: a) a escolaridade de pais e atletas; b) a formação profissional no futebol; b) o tempo gasto com treinamento; c) o meio de transporte e o tempo nos deslocamentos para o clube; d) o tipo de formação escolar; e) o tempo gasto na rotina escolar; f) o meio de transporte e o tempo nos deslocamentos para a escola; g) hábitos culturais: estudo, cinema, internet, televisão e leitura. Para determinar a classe social dos atletas foi aplicado um questionário socioeconômico de acordo com os critérios da Associação Brasileira de Empresas de Pesquisa (ABEP) que levantava bens de consumo familiar. $\mathrm{O}$ roteiro de entrevistas semiestruturadas foi construído a partir das categorias supracitadas com o intuito de aprofundar os elementos de análise.

\section{Procedimentos de coleta de dados}

A coleta de dados foi realizada diretamente nos clubes de futebol no Estado do Rio de Janeiro. O instrumento foi aplicado com o auxílio de cinco entrevistadores treinados no preenchimento do formulário das entrevistas estruturadas. A conduta adotada pelos entrevistadores foi a de informar o tempo médio de cada entrevista, algo em torno de 10 minutos, no momento em que os atletas eram liberados pelos responsáveis no clube. As entrevistas semiestruturadas e as notas nos diários de campo foram realizadas pelo pesquisador supervisor que acompanhou os entrevistadores durante o trabalho de campo.

\section{Análise estatística}

Os dados são apresentados em forma de média e desvio padrão, complementada, quando necessário, ao cálculo de prevalência. Os indivíduos foram agrupados por categoria (sub-13, sub-15, sub-17 e sub-20) e turno escolar (manhã, tarde e noite).

Para a análise dos dados observados foi construída uma planilha no programa Microsoft Excel e a análise estatística foi feita no programa SPSS ${ }^{\mathrm{d}}$ para Windows (versão 19.0). 


\section{Resultados}

No sentido de entender se a formação profissional no futebol pode criar obstáculos para permanência e dedicação dos atletas à escola básica, analisamos a flexibilização das normas escolares, a faixa salarial média das famílias dos atletas dos clubes grandes e dos clubes pequenos, atletas que estudam e atletas que não estudam, a escolha do turno escolar, o consumo cultural e a dedicação aos estudos.

\section{Atletas estudantes $x$ atletas não estudantes}

Dos 417 atletas entrevistados, 345 (82,7\%) frequentavam a escola, enquanto que $72(17,3 \%)$ náo estudavam por abandono ou conclusão do ensino básico. Desses 72, 46 concluíram o ensino médio e 26 abandonaram os estudos. Ainda sobre os atletas que não estudavam, observamos que $15(57,7 \%)$ desistiram da continuidade nos estudos quando estavam próximos de concluírem o ensino médio, sendo seis $(23,1 \%)$ no $1^{\circ}$ ano do ensino médio e nove $(34,6 \%)$ no $2^{\circ}$ ano do mesmo segmento da educação básica. Vimos que $10(38,5 \%)$ dos atletas que abandonaram a escola o fizeram ainda no $2^{\circ}$ segmento do ensino fundamental, com equilíbrio na distribuiçáo pelas séries. Apenas um atleta $(3,8 \%)$ não passou pelo $1^{\circ}$ segmento do ensino fundamental. Ele abandonou a escola na $3^{\circ}$ série/ $4^{\circ}$ ano. Desse total de atletas que abandonaram a escola, temos um percentual de $65 \%$ de jovens que repetiram ao menos um ano escolar. Este valor representa uma proporção muito além do encontrado na amostra total, cujo resultado foi de $36,7 \%$ de atletas que reprovaram pelo menos um ano na trajetória escolar.

Na FIGURA 1, podemos observar a distribuição percentual dos atletas que estudavam, os que concluíram o ensino médio e os que abandonaram a escola, a partir do controle pela faixa salarial familiar estimada. Os dados apontam que os atletas que abandonaram os estudos são os que se situam nas famílias de renda mais baixa. Entre esses não encontramos nenhum atleta na faixa de renda mais alta. No entanto, a média salarial dos três grupos apresentados é muito semelhante. A média da faixa salarial estimada dos atletas que se mantém na escola é de $\mathrm{R} \$ 2.436,00$, dos que concluíram o ensino médio é de $R \$ 2.474,00$ e dos atletas que abandonaram os estudos fica na faixa dos $\mathrm{R} \$ 2.359,00$.

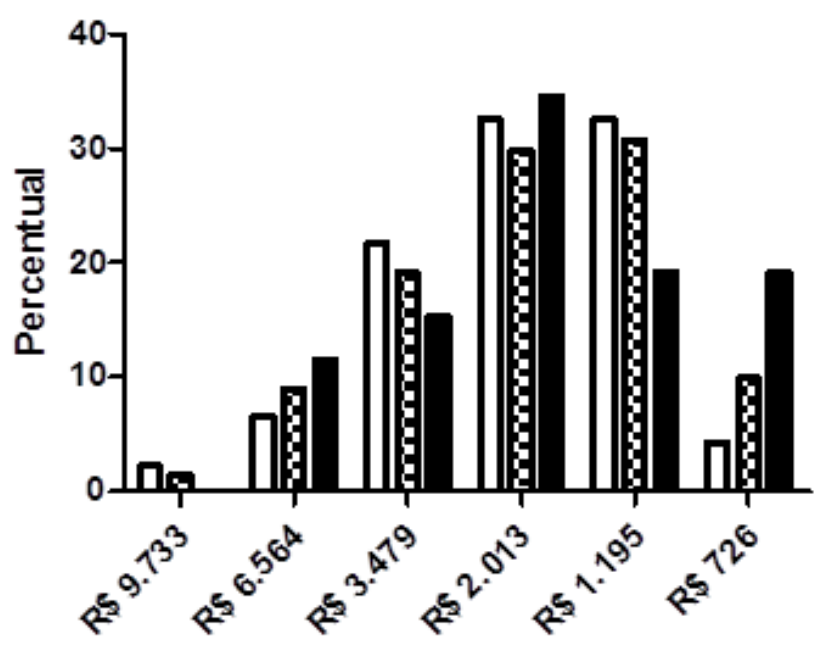

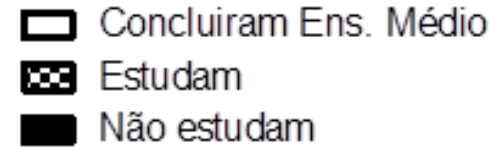

Faixa salarial

FIGURA 1 - Distribuição percentual da faixa salarial dos atletas que concluíram o ensino médio, que ainda estudam e os que abandonaram a escola.

\section{Clubes grandes $x$ clubes pequenos}

No sentido de entendermos de forma mais detalhada o perfil dos atletas desmembramos os dados educacionais pelo tipo de "status" do clube no mercado do futebol fluminense, pela renda estimada das famílias e pela categoria profissional. 
TABELA 2 - Distribuição da frequência e percentual da faixa salarial por status do clube e categoria.

\begin{tabular}{ccccccccc}
\hline \multirow{2}{*}{$\begin{array}{c}\text { Faixa } \\
\text { salarial }\end{array}$} & \multicolumn{9}{c}{ Clubes grandes } & \multicolumn{4}{c}{ Clubes pequenos } \\
\cline { 2 - 8 } & Sub-13 & Sub-15 & Sub-17 & Sub-20 & Sub-13 & Sub-15 & Sub-17 & Sub-20 \\
\hline R \$ 9.733 & $0(0,0 \%)$ & $0(0,0 \%)$ & $1(4,2 \%)$ & $0(0,0 \%)$ & $2(4,5 \%)$ & $2(2,3 \%)$ & $0(0,0 \%)$ & $1(1,2 \%)$ \\
R\$ 6.564 & $3(9,4 \%)$ & $4(16,0 \%)$ & $7(29,2 \%)$ & $3(12,5 \%)$ & $2(4,5 \%)$ & $4(4,5 \%$ & $2(2,1 \%)$ & $5(5,9 \%)$ \\
R\$ 3.479 & $5(15,6 \%)$ & $4(16,0 \%)$ & $3(12,5 \%)$ & $11(45,8 \%)$ & $10(22,7 \%$ & $16(18,2 \%$ & $29(30,5 \%)$ & $6(7,1 \%)$ \\
R\$ 2.013 & $8(25,0 \%)$ & $8(32,0 \%)$ & $6(25,0 \%)$ & $5(20,8 \%)$ & $14(31,8 \%)$ & $22(25,0 \%)$ & $30(31,6 \%)$ & $35(41,2 \%)$ \\
R \$ 1.195 & $13(40,6 \%)$ & $7(28,0 \%)$ & $6(25,0 \%)$ & $5(20,8 \%$ & $14(31,8 \%$ & $26(29,5 \%)$ & $30(31,6 \%)$ & $26(30,6 \%)$ \\
R\$ 726 & $3(9,4 \%)$ & $2(8,0 \%)$ & $1(4,2 \%)$ & $0(0,0 \%)$ & $2(4,5 \%$ & $18(20,5 \%)$ & $4(4,2 \%)$ & $12(14,1 \%)$ \\
\hline
\end{tabular}

Quando comparamos a faixa salarial familiar dos atletas divididos pelo "status" do clube no mercado do futebol, encontramos que os atletas que jogam nos clubes grandes apresentam uma maior renda. A média salarial das famílias dos atletas dos clubes pequenos é de $\mathrm{R} \$ 2.257,00$ enquanto que a dos atletas dos clubes grandes é de $\mathrm{R} \$ \mathrm{R} \$ 2.883,00$. Se separarmos esses valores pelas categorias, teremos a seguinte configuração: a média salarial para atletas dos clubes pequenos nas categorias sub- 13 e sub- 15 é de $\mathrm{R} \$ 2.371,00$, para os atletas das duas categorias mencionadas, a média tem um decréscimo de $9,6 \%$, chegando a $\mathrm{R} \$ 2.143,00$. Entretanto, para os atletas dos clubes grandes existe leve um aumento entre as categorias. Os atletas das sub-13 e sub- 15 apresentaram média de $\mathrm{R} \$ 2.430,00$, os atletas das categorias sub-17 e sub-20 apresentaram um valor $37,3 \%$ maior, alcançando a média de $\mathrm{R} \$ 3.335,00$. Portanto, os atletas das categorias finais dos clubes grandes do Estado do Rio de Janeiro, possuem renda familiar 55,6\% maior que seus pares dos clubes considerados pequenos. Este dado sugere que as famílias dos jogadores em formação nos times grandes possuem melhor nível socioeconômico e/ou a renda familiar é aumentada pelos rendimentos auferidos pelos atletas ainda em processo de formação.
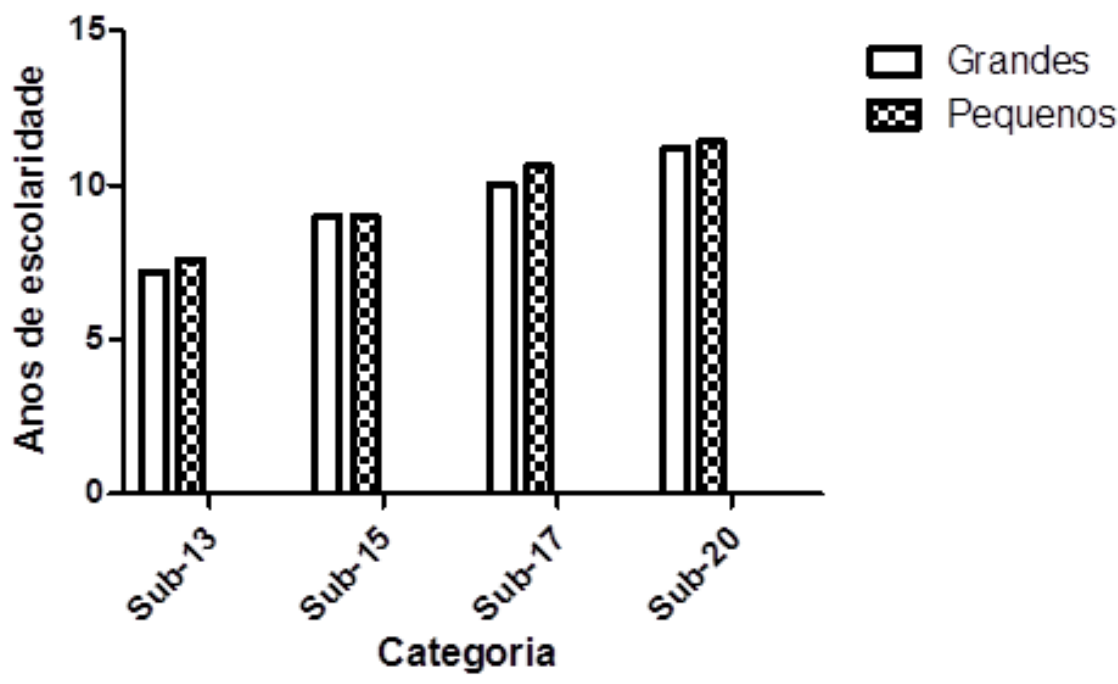

FIGURA 2 -Anos de escolaridade por "status" do clube e categoria.

Se compararmos a distribuição dos anos de escolaridade dos atletas separados pelo "status" do clube, observaremos que os atletas dos clubes pequenos apresentam mais anos de escolaridade. Na categoria sub-13, a diferença é de 0,4 anos a mais para os clubes pequenos. Na sub-15, há um empate. Na sub-17 e sub-20, os clubes pequenos voltam a apresentar vantagem, 0,6 e 0,4 anos, respectivamente. No entanto, a diferença apresentada é muito pequena, e não podemos afirmar que a formação nos clubes grandes dificulta mais a permanência ou a progressão na escola.

\section{Turno escolar}

Ao compararmos o turno em que os atletas frequentam as salas de aula em relação às categorias tivemos a seguinte distribuição: na sub-13, todos estudam pela manhã e isso ocorre porque todos os clubes que 
participaram da amostra realizavam o treinamento dessa categoria no período da tarde. Já na sub-15, são 73 atletas que estudam à tarde, 19 deles estudam pela manhã e 20 à noite. No que diz respeito ao treinamento na categoria sub-15, em quase todos os clubes essa atividade ocorre pela manhâ; somente em alguns poucos clubes os jogadores treinam à tarde. Com os atletas da sub-17, observamos um acréscimo no número de atletas estudando no período noturno: sáo 57 dos 113 respondentes; outros 40 estudam à tarde e apenas 16 pela manhã. Os treinamentos dos jogadores da sub-17 ocorrem de forma semelhante aos da sub-15, na maioria das vezes ocorre no período da manhá. Entre os atletas da categoria sub-20, a grande maioria estuda no turno da noite. Os treinamentos semanais dessa categoria são, em geral, matutinos o que, todavia, não exclui a possibilidade que sejam marcados treinos à tarde ou viagens. Observemos que os atletas que estão mais próximos da profissionalização acabam por aumentar a participaçáo na escola noturna. Pode-se pensar que quanto maior a idade na categoria futebolística maior serão as matrículas no ensino noturno.

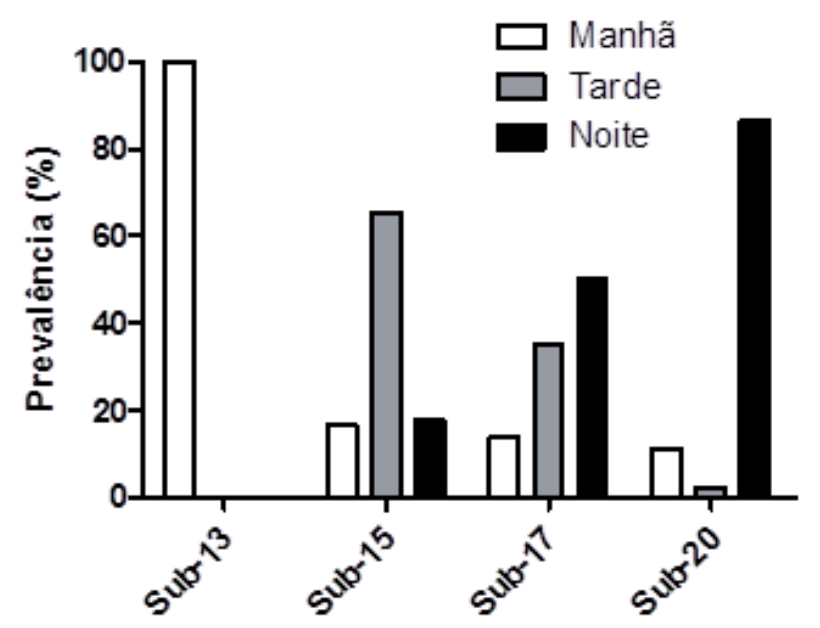

FIGURA 3 - Distribuição percentual do turno de frequência à escola por categoria.

\section{Dedicação aos estudos e consumo cultural}

A exigência, dedicação, disciplina e competição presente no processo de formação no futebol, talvez, incida no foco que o atleta tenha no processo de escolarização. O progresso no processo de profissionalização condiciona de certa forma a escolha do turno escolar. Se tomarmos o consumo cultural dos atletas, observaremos que a leitura não foi efetivamente socializada entre eles e o hábito de estudar se faz presente num baixo percentual. Entre o contingente da nossa amostra, $63,3 \%$ indicaram que raramente ou nunca leem livros e apenas $13,9 \%$ declararam que estudam para as provas ou fazem as tarefas escolares passadas para casa. Tais proporçôes sugerem um baixo investimento na incorporação de capital cultural e na dedicação aos estudos e tarefas escolares. Em contraposição, quando o assunto é consumo do futebol, 88,2\% afirmaram que sempre assistem partidas de futebol na televisão.

\section{Flexibilização das normas escolares}

A flexibilizaçáo das normas escolares ocorrem de forma contingencial no cotidiano escolar. Por exemplo, um atleta da categoria sub-15, de um dos principais clubes do Rio de Janeiro, declarou em entrevista que quando faltava à escola em função dos jogos ou viagens justificava suas faltas com uma declaraçáo do clube ou com um atestado médico. Quando interrogado pelo entrevistador o atleta diz existir uma flexibilização da escola por atender a boa parte dos atletas de seu clube: "Não dá problema porque aqui é como se fosse uma escola do [clube] (...) porque a maioria dos jogadores estuda lá" (Entrevista gravada no dia 19 de abril de 2009). Noutro caso, os atletas, de um clube grande no Rio de Janeiro, afirmaram que frequentavam uma escola privada que tinha flexibilidade para atletas, isto é, as aulas ocorriam três vezes por semana em apenas um turno. Esses mesmos atletas tinham bolsa de estudo e além de representarem seus clubes em competições também eram atletas da referida escola em torneios estudantis (Diário de campo, 27 de outubro de 2009).

Caso semelhante, encontramos com outro atleta entrevistado. Perguntamos como ele conseguia conciliar os treinamentos, as viagens, convocaçôes para seleção e troca constante de categorias, pois este atleta apesar de possuir idade para jogar na categoria sub17 , ele treinava constantemente com os profissionais e disputava jogos com a equipe sub-20. Segundo 
as palavras do atleta, na sua escola era tudo mais fácil de lidar, pois havia a possibilidade de estudar em diferentes turnos durante o mesmo ano letivo, conforme as suas necessidades. Observemos a sua fala a seguir:

\section{Discussão}

A imagem socialmente partilhada que a formação dos atletas nas categorias de base cria empecilhos ou abandono da escola em função das demandas e objetivos do futebol profissional foi parcialmente refutada. Os dados levantados nos permitem afirmar que a formação no futebol não é empecilho para permanência dos atletas na escola, pois os dados globais indicam que apenas $6,2 \%{ }^{26}$ dos atletas em formação no futebol do Rio de Janeiro abandonaram a escola. Todavia, ainda que permaneçam na escola, vimos também que essa sentença só se faz verdadeira quando associada a mecanismos que flexibilizam as normas regulares da escola. Logo, não se pode dizer de imediato que a permanência na escola signifique uma maior dedicação aos bancos escolares e, possivelmente, uma trajetória de sucesso na instituição escolar.

Podemos imaginar que a situação dos jovens atletas de futebol do Estado do Rio de Janeiro regularmente matriculados na instituição escolar é uma forma de cumprimento do estabelecido nas leis nacionais, as quais condicionam a relação entre a profissionalização de jovens com a escola básica ${ }^{13-15}$. Nos textos legais, institui-se que os jovens devem estar matriculados na educação básica. Se considerarmos que o atleta vive uma dupla carreira e a carreira de jogador de futebol pode ser considerada, em determinada fase, equivalente a de um jovem aprendiz da profissáo, o empregador deve, portanto, oferecer todas as condiçóes para que o jovem tenha plenas possibilidades de frequentar a escola no dia a dia. De fato, a permanência dos atletas na escola pode simplesmente significar na amostra selecionada o cumprimento adequado da lei. Essa interpretação significa uma das faces da moeda.

Noutra direção, devemos refletir a forma como os jovens atletas continuam frequentando a instituiçáo de ensino. Os dados sobre o turno escolar e os qualitativos, sobretudo, indicam que há uma fragilidade na negociação entre a escola e o clube, uma vez que a escola se coloca na condição de facilitadora para que o atleta continue investindo na sua formação no clube.

Sugerimos que possa haver uma dificuldade no controle e fiscalização do cumprimento dessas
Aqui é mais tranquilo, estudo aqui dentro do clube e... a gente consegue conciliar bem os treinos. Aqui tem a facilidade de, se não puder ir [à escola] de tarde, eu posso ir de manhã (Entrevista gravada no dia 16 de agosto de 2009). normas, o que ainda pode ser agravado pela falta de interesse dos jovens pela escola e pelo forte apelo midiático associado ao esporte, principalmente o futebol. Para além dos problemas de falta de política específica que estruture a formaçáo dos atletas em conciliaçáo com a escola básica, temos os entraves que impedem que a escola proporcione uma educação de qualidade e de acesso a todos, mesmo a partir do processo de universalizaçáo assistido nas duas últimas décadas ${ }^{16}$. O sistema educacional brasileiro é alvo de uma crítica intensa que indica as possíveis inequidades de acesso às oportunidades educacionais. RibeIRo ${ }^{17}$ apresentou que as desigualdades de oportunidades no sistema educacional brasileiro persistem mesmo com as mudanças que caminham na direção da universalização da educação básica. $\mathrm{O}$ autor indicou que as variáveis "status ocupacional do pai" e "escolaridade da máe" - usadas como representação de nível socioeconômico - seriam as principais explicaçóes para as diferenças de acesso aos níveis de ensino. Conforme os alunos vão avançando nas séries escolares, aqueles que detinham menor índice socioeconômico tiveram maiores dificuldades de transição entre um nível de ensino e o seu subsequente.

A legislação avança tornando, a partir de 2011, a escolarização obrigatória dos quatro aos 17 anos, compreendendo 14 anos de estudo. Os indicadores da Pesquisa Nacional por Amostra de Domicílios (PNAD) de 1995 apontavam que $93 \%$ das crianças entre sete e 14 anos frequentavam a escola. Essa taxa obteve um aumento significativo entre 1995 e 2007, atingindo a marca de $98 \%$ de alunos frequentando o ensino fundamental ${ }^{16}$. Apesar desses avanços, SchwartzMan e Cossío $^{18}$ indicam que "quase totalidade dos alunos das escolas públicas, em todos os níveis, têm desempenho inferior ao prescrito pelas respectivas séries, e muitos permanecem como analfabetos funcionais ${ }^{\text {a através dos }}$ anos" (p.11). Essa afirmaçáo pode ser corroborada pelo insuficiente rendimento das escolas no Sistema Nacional de Avaliação da Educação Básica (SAEB ${ }^{f}$ ).

Mesmo náo impedindo a permanência na escola, encontramos um percentual residual de atletas que 
a abandonou. Podemos afirmar que a faixa etária a partir dos 15 anos se constitui em um momento crítico para os jovens, e é nesse momento que a escola básica exige uma demanda maior de tempo e investimento. Pensando nisso, a escola não parece despertar o interesse para os jovens. O esporte parece ter atrativos, com oportunidades mais tangíveis, nas representaçóes e sonhos desses jovens, que a escola. Para além dos problemas de conciliaçáo entre escola e formaçáo esportiva, Schwartzman e Cossío ${ }^{18}$ indicam que o maior fator de contribuiçáo para o afastamento e a desistência de jovens da escola tem a ver exatamente com a qualidade do ensino das escolas do Brasil, ou seja, não é simplesmente uma dedicação e a chance do futuro promissor que levam os atletas a colocarem a escola em segundo plano ou até mesmo abandonarem-na, mas sim a possibilidade de alcançar o sucesso profissional através da prática esportiva. As pesquisas sobre evasão escolar também indicam que o principal motivo de abandono escolar até o ano de 2006, dentre outros apresentados, é a falta de interesse intrínseco na escola com 43,3\% das respostas, ${ }^{g, 16}$. Os argumentos dos autores supracitados indicam que, apesar dos avanços educacionais promovidos no Brasil nas últimas duas décadas, a escola brasileira é de baixa qualidade e desinteressante. $\mathrm{O}$ que vai ao encontro com os achados de AAES $^{19}$ quando indica que "[...] pode-se concluir que o padráo de funcionamento da Escola Pública é responsável pela reprodução, no Brasil, de uma pirâmide educacional que reserva uma trajetória escolar curta a maioria social e uma trajetória escolar longa a minoria social.” (p.167).

Uma das estratégias de flexibilização das normas escolares mais presentes foi a vista na FIGURA 3, que sugere que os jovens atletas escolhem adequar o turno e o tipo de exigência da escola em função do período de treinamento. A concentração progressiva para aqueles que permanecem na carreira a partir da categoria sub- 17 e sub-20 no ensino noturno indica que a aproximaçáo da profissionalização condiciona a escolha do turno e o tipo de escola. A taxa crescente de matrículas no ensino noturno pode sugerir que a escolha da escola noturna se torna uma opçáo para a conciliação entre futebol e escola, devido às exigências cada vez maiores na formação esportiva. BARRETO ${ }^{20}$ indicou, em seu estudo, dificuldades de conciliação entre a formação esportiva e escolar de atletas de futebol de Minas Gerais, pois, os dados apontaram um aumento significativo no número de matrículas no ensino noturno a partir dos 15 anos. SOARES et al. ${ }^{21}$ encontraram resultados semelhantes, na pesquisa sobre os jovens em processo de profissionalizaçẫo no turfe no Rio de Janeiro. A transição para o período noturno pode afetar negativamente a carreira escolar dos atletas, pois como é sabido o ensino noturno na educação básica tem, em geral, menor qualidade que o diurno ${ }^{22}$. Ademais, o currículo da escola noturna não leva em conta as peculiaridades do estudante trabalhador e é de qualidade questionável ${ }^{23}$. Observemos ainda que a maioria dos atletas frequenta a escola após uma carga intensa de esforço corporal. $\mathrm{O}$ cansaço motivado pela rotina de treinamento pode influenciar no grau de concentraçáo na sala de aula. Assim, a relaçáo entre desempenho e permanência na escola talvez esteja associada ao tipo de contrato informal que a escola privada e as escolas públicas noturnas estabelecem com seus alunos.

As dificuldades de conciliação entre a carreira no esporte e na escola não são exclusividade brasileira. Embora no Brasil existam poucas experiências de escolas voltadas para atletas de alto-rendimento, essas vivências ainda precisam de estudos que incidam sobre a avaliaçáo da qualidade da formaçáo do aluno-atleta. Esse é o caso do Ginásio Experimental Olímpico (GEO) e das iniciativas de clubes que instituíram escolas ou convênios para seus atletas. Todavia, estudos internacionais mostram que a tentativa de alguns países em estabelecer programas de mediação entre a carreira esportiva e escolar de jovens atletas náo consegue mais do que o adiamento de algumas provas e, quiçá, abonos de falta. Embora com todos os problemas, tais programas e escolas especiais indicam a preocupação das políticas em tratar essa parte da população de jovens que tenta se inserir no mercado esportivo ${ }^{4,24}$. Porém, essas conquistas nos programas especiais não avançaram muito além do que notamos em relaçáo aos que os jovens atletas da nossa pesquisa conquistam de modo informal diante da fragilidade da instituição escolar no Brasil.

Os estudos apontam que a conciliação entre a escola e a formação de atletas de alto-nível apresentam dificuldades de gestão tanto para os programas voltados para conciliar formação esportiva e escola, quanto para as agências que agem de forma livre apenas com a exigência de cumprirem o preceito legal de matricular seus atletas na escola básica. No Brasil, esse tema ainda não ganhou peso na agenda das federaçôes esportivas, das políticas governamentais e dos sistemas de ensino. Por exemplo, o Programa Bolsa-atleta do Governo Federal, na categoria estudantil, exige do atleta beneficiado desempenho de alto-nível em sua modalidade esportiva e a comprovação da matrícula escolar. No caso das instituiçôes esportivas, voltadas para a formação no futebol, temos iniciativas isoladas que estabelecem convênios com escolas privadas ou 
possuem escolas com regime especial para seus atletas no interior dos centros de formação. Destacamos que essas experiências são raras e carecem de avaliação. A literatura internacional aponta que mesmo as escolas com programas para atletas poucos conseguem flexibilização além de dispensas, remarcaçóes de provas.

CAPuT-Jogunica et al. ${ }^{25}$ indicaram a necessidade de incentivo para os jovens atletas obterem um equilíbrio adequado entre a educação e o desenvolvimento do esporte e que são necessários elevados níveis de flexibilização para suporte aos atletas. Os autores acima mostraram que têm sido feitos esforços na maioria dos países europeus tentando sanar a dificuldade na conciliação entre esporte de alto nível e escola, no entanto, muitas vezes não são suficientes para dar uma formação escolar de qualidade se os atletas quiserem alcançar o alto-nível esportivo. AquilinA ${ }^{5}$ também encontrou dificuldades na conciliação entre esporte de alto rendimento e formação escolar. O autor enfatiza a necessidade da dedicaçáo ao esporte de atletas de alto-nível, deixando em segundo plano outros aspectos da vida fora do esporte devido ao pouco tempo disponível. O autor ainda salienta a necessidade dos atletas possuírem um dupla carreira, pois, são poucos os atletas de elite que são recompensados suficientemente financeiramente. Ainda sobre as dificuldades de conciliação, temos o estudo de Borggrefe e Cachay 1 que indicam que a carreira de atleta exige uma formação continua e sistemática, com mais de 20 horas semanais de treinamento, disputas de competiçóes, ficando o atleta semanas ou meses longe de casa. Além disso, esses são compromissos que colidem com a carreira escolar, pondo em risco qualificaçóes educacionais.

Os dados indicam que a profissionalização no esporte talvez incida sobre o foco que o atleta tenha sobre o processo de escolarização. Todavia, o futebol e outros esportes que exigem dedicação integral com possibilidades de retorno financeiro se tornam um complicador para dedicação e continuidade dos estudos, principalmente, para aqueles que completaram o ensino médio.

$\mathrm{O}$ fato de os atletas permanecerem na escola não é indicativo de que haja uma maior dedicação aos estudos. Ao contrário, os dados mostraram que os atletas apresentam baixo consumo de bens culturais, pouco cumprem as obrigaçóes e as tarefas escolares. Ainda que o índice de abandono escolar e o de reprovação dos atletas sejam baixos, retomamos a ideia da flexibilização das normas regulares. Por esse motivo, imaginamos que haja um baixo poder de comparação entre os indicadores dos atletas da nossa amostra com a população de estudantes de um modo geral.
Porém, podemos sugerir que o perfil dos atletas dessa investigação não difira muito dos alunos não-atletas ou trabalhadores de ocupaçôes ordinárias.

Talvez um agravante para a relação da escola com seus alunos tenha se mostrado presente na nossa investigação. Quando afirmamos que o futebol não é um limitador para a permanência do jovem na escola, apoiamo-nos nos dados sobre o baixo índice de evasão escolar dos atletas da nossa amostra. Além disso, mostramos que as normas escolares são perfeitamente negociáveis para esses atletas. Diante disso, questionamos se a própria escola não vem se dando conta da sua ineficiência e, por esse motivo, permite que os alunos que apresentam oportunidades por outras vias de profissionalização venham a ter condescendência da escola quanto ao cumprimento das exigências escolares. Essa pode ser uma afirmativa um tanto crítica e que carece de aprofundamento através de outras pesquisas focadas na questão da flexibilidade das normas escolares para atletas e náo-atletas. Mas, por enquanto, vamos atentar a dois autores que auxiliam a pensar os problemas da escola brasileira e a diversidade de expectativas dos jovens diante da escolarização. SchWARTZMAN ${ }^{26}$ adverte que o sistema educacional brasileiro ao tratar igualmente os seus distintos alunos, tende a frustrar as expectativas de uma maioria ávida pelo sucesso. $\mathrm{O}$ segundo autor é DuBET ${ }^{27}$ que, ao falar sobre o que seria uma escola justa, afirmou que ao submetermos à mesma lógica escolar os alunos já vencidos por ela, cairíamos na armadilha de negarmos a esses jovens o direito ao acesso ao aprendizado e à educação. Essas perspectivas de análise nos auxiliam a pensar que a escola não consegue lidar com as formas de resistência que se apresentam a partir da expectativa e necessidades da população de jovens por ela assistida. No caso dos atletas, a resistência deles aparece na medida em que propóem meios para que a escola deixe de cumprir com o seu regimento legal. Levando isso em consideração, a escola dos atletas investigados abre mão dos aparatos legais e perde no confronto de interesses com os clubes esportivos ou com os próprios atletas sua primordial função, a saber: a transmissão do capital cultural institucionalizado. Talvez, por esse motivo e por náo saber como tratar essa parcela da juventude dividida entre o esporte e a educação formal, a escola opte por flexibilizar suas obrigaçóes e normas regulares.

O presente estudo pôs à prova a crença de que os jovens atletas de futebol tinham pouca ou nenhuma base na formação escolar. Como vimos, essa afirmativa do senso comum não se sustenta de forma plena, uma vez que os atletas permanecem na escola. Porém, essa permanência é mediada por mecanismos que 
podem afetar negativamente a sua trajetória escolar. Trata-se de um estudo exploratório que levantou muitas questóes e acaba por abrir outras que não dá conta no escopo desse estudo. Sugerimos que as questôes aqui tratadas sejam também fruto para outras pesquisas de natureza empírica que tratem do grupo de atletas e não-atletas que decidem desempenhar a dupla carreira entre escola e trabalho, no esporte ou não. Temos que buscar entender as especificidades dessa parte da juventude que apresenta demandas próprias e que pouco é explorada nos estudos educacionais. Os dados podem insinuar que quanto mais investimentos o atleta realiza em sua carreira, maior será a probabilidade de secundarizar a escola.

\title{
Notas
}

a. Trata-se de uma escolar da rede municipal do Rio de Janeiro vocacionada, voltada para atletas, e que atende a alunos do ensino fundamental do segundo segmento.

b. O Clube de Regatas Vasco da Gama oferece ensino fundamental e médio desde 2004 dentro das instalaçóes de São Januário. A escola é um convênio com um colégio particular. $\mathrm{O}$ ensino é oferecido para todos os atletas de todos os esportes oferecidos pelo clube. Os atletas estudam sempre no contra turno de treinamento.

c. De voleibol, tênis, natação e triátlon.

d. Statistical Package for the Social Sciences.

e. Definido como indivíduos que não possuem autonomia nas competências de leitura e escrita.

f. O Sistema Nacional de Avaliação da Educação é uma medida do Programa Todos pela Educação com o objetivo de avaliar o desempenho dos alunos segundo uma média estipulada como adequada para três séries capitais referentes à escola básica. g. Análise a partir da base de dados do PNAD 2004 e 2006.

\begin{abstract}
Educational profile of young soccer players in the State of Rio de Janeiro

The study aimed to describe the educational profile of athletes who work in the State of Rio de Janeiro and in the period of basic schooling. The study had a quantitative and qualitative approach. Structured interviews were conducted with non-probability sample consists of 417 players of the base categories, inscribed in the year 2009 in the Soccer Federation of Rio de Janeiro State and 30 semi-structured interviews. The results showed that the athletes remain at the school; however the flight rotation and low cultural capital can negatively affect his career. To become a professional of soccer is a project which involves all athlete's family, and maybe this is what makes him not prioritize his formal education. Our data suggest that the more the athlete invest in his career, the more the probability of putting school in the background.
\end{abstract}

KEY WORDS: Sport; School; Professional formation; Youth players.

\section{Referências}

1. Borggrefe C, Cachay K. "Dual careers": the structural coupling of elite sport and school. Eur J Sport Soc. 2012;9:57-80.

2. Metsa-Tokila T. Combining competitive sports and education: how top-level sport became part of the school system in the Soviet Union, Sweden and Finland. Eur Phys Educ Rev. 2002;8:196-206.

3. Hickey C, Kelly, P. Preparing to not be a footballer: higher education and professional sport. Sport Educ Soc. 2008; 13:477-94.

4. Christensen MK, Sørensen JK. Sport or school? Dreams and dilemmas for talented young Danish football players. Eur Phys Educ Rev. 2009;15:115-37.

5. Aquilina D. A study of the relationship between elite athletes educational development and sporting performance. Int J Hist Sport. 2013;30:374-92. 
6. Kay T. Sporting excellence: a family affair? Eur Phys Educ Rev. 2000;6:151-69.

7. Damo A. Do dom a profissão: uma etnografia do futebol de espetáculo a partir da formação de jogadores no Brasil e na França. São Paulo: Aderaldo \& Rothschild; 2007.

8. Epiphanio EH. Conflitos vivenciados por atletas quanto à manutenção da prática esportiva de alto rendimento. Est Psicol. 2002;19:15-22.

9. Marques MP, Samulski DM. Analise da carreira esportiva de jovens atletas na transiçáo da fase amadora para a fase profissional: escolaridade, iniciação, contexto sócio familiar e planejamento da carreira. Rev Bras Educ Fís Esporte. 2009;23:103-19.

10. Souza CAM, Bartholo TL, Vaz AF, Soares AJG. Difícil reconversão: futebol, projeto e destino em meninos brasileiros. Horiz Antropol. 2008;14:85-111. Disponível em: http://www.scielo.br/pdf/ha/v14n30/a04v1430.pdf.

11. Soares AJG, Melo LBS. O tempo do futebol e da escola. XXXIV Reunião Anual da Associação Nacional de Pós-graduação e Pesquisa em Educação: educação e justiça social; 2-5 out. 2011; Natal, BR. Natal: AMÈD; 2011. Disponível em: http://34reuniao.anped.org.br/images/trabalhos/GT14/GT14-859\%20int.pdf.

12. Soares AJG, Melo LBS, Bartholo TL, Velarde GC, Ribeiro CHV, Santos TM. Time for football and school: an analysis of young brazilian players from Rio de Janeiro. Estud Sociol. 2013;31:437-69.

13. Brasil. Decreto-lei n. 5.452, de $1^{\circ}$ de maio de 1943. Aprova a Consolidação das Leis do Trabalho. Diário Oficial da União, Brasília (9 ago. 1943); Sec.1:11937. Disponível em: http://www2.camara.gov.br/legin/fed/declei/1940-1949/ decreto-lei-5452-1-maio-1943-415500-norma-pe.html.

14. Brasil. Lei Federal n. 8069, de 13 de julho de 1990. Dispóe sobre o Estatuto da Criança e do Adolescente. Diário Oficial da União, Brasília (16 jul. 1990); Sec.1:13563.

15. Brasil. Lei n. 9394, de 20 de dezembro de 1996. Estabelece diretrizes e bases da educação nacional. Diário Oficial da União, Brasília (23 dez. 1996); Sec.1:27833.

16. Neri MC. O paradoxo da evasão e as motivaçóes dos sem escola. In: Veloso F, organizador. Educação básica no Brasil: construindo o país do futuro. Rio de Janeiro: Campus; 2009. p.25-50.

17. Ribeiro CAC. Desigualdade de oportunidades no Brasil. Belo Horizonte: Argvmentvm; 2009.

18. Schwartzman S, Cossio MB. Juventude, educação e emprego no Brasil. Cad Adenauer. 2007;2:51-65.

19. Saes DAM. Escola pública e classes sociais no Brasil atual. Linhas Crít. 2008;14:165-76.

20. Barreto PHG. Flexibilização escolar a atletas em formação alojados em centros de treinamento no futebol: um estudo na toca da raposa e na cidade do galo [dissertação]. Espirito Santo(ES): Universidade Federal do Espírito Santo. Disponível em: http://labec-ufrj.com/dissertacoes/Dissertacao_versao_final\%20Paulo\%20Henrique.pdf.

21. Soares AJG, Rocha HPA, Costa FR. A escola dos jóqueis: a aposta de carreira do aluno atleta. XV Congresso Brasileiro de Sociologia; 2011; Curitiba, BR. Curitiba: SBS; 2011. Disponível em: http://www.sistemasmart.com.br/sbs2011/ arquivos/30_6_2011_15_53_43.pdf.

22. Togni AC, Soares MJ. A escola noturna de ensino médio no Brasil. Rev Iberoamericana Educ. 2007;44:61-76. Disponível em: http://redalyc.uaemex.mx/redalyc/pdf/800/80004406.pdf.

23. Corrochano MC, Nakano M. Jovens, mundo do trabalho e escola. In: Sposito MP, coordenador. Juventude e escolarização (1980-1998). Brasília: MEC/INEP/COMPED; 2002. p.95-134.

24. Henry I. Elite athletes and higher education: lifestyle, balance and the managment of sporting and educational performance. Brusselles: International Olympic Committee; 2010.

25. Caput-jogunica R, Ćurković S, Bjelić G. Comparative analysis: support for student-athletes and the guidelines for the universities in southeast. Eur Sport Sci. 2012;1:21-6.

26. Schwartzman S. O viés acadêmico na educação brasileira. In: Bacha E, Schwartman S, organizadores. Brasil: a nova agenda social. Rio de Janeiro: Casa das Garças; 2011.

27. Dubet F. O que é uma escola justa? Cad Pesq. 2004;123:539-55. Disponível em: http://www.scielo.br/pdf/cp/v34n123/ a02v34123.pdf. 
Melo LBS, et al.

\section{Agradecimentos}

Este estudo recebeu auxílio financeiro da FAPERJ e do CNPq.

ENDEREÇO

Leonardo Bernardes Silva de Melo

R. Lúcio Alves, 345 - Bloco 2 - apto. 102 21863-430 - Rio de Janeiro - RJ - BRASIL

e-mail: leonardo.melo@globo.com
Recebido para publicação: 31/01/2013

1a. Revisão: 18/01/2014

2a. Revisão: 15/02/2014

3a. Revisão: 09/07/2014

Aceito: 11/07/2014

628 • Rev Bras Educ Fís Esporte, (São Paulo) 2014 Out-Dez; 28(4):617-28 